\title{
Ivanov-Smolensky conditioning in adults and children using an electromyographic
}

\section{response measure}

KENNETH B. SOLBERG, TIMOTHY E. TYRE, and G. MICHAEL STINSON, Saint Mary's College, Winona, Minn. 55987

Conditioning using the method of Ivanov-Smolensky was investigated in children and adults, with measures taken of both overt and EMG responses. Neither group showed evidence of conditioning under the overt measure. However, the EMG measure showed clear evidence of acquisition for both groups, with children showing no extinction and the adults immediate extinction. It was suggested that while Ss inhibited overt CRs, the EMG measure was sensitive in detecting a preparatory component of the UCR, and that this component was readily conditioned.

The present investigation compared Ivanov-Smolensky conditioning in adults and children using both an overt and an electromyographic (EMG) measure of responding. Ivanov-Smolensky conditioning is a classical-conditioning paradigm in which a neutral CS is paired with a command to make a voluntary response. The command serves as the UCS, and the voluntary response to the command is the UCR. Responses anticipatory to the command or responses to the CS alone as during extinction are CRs. A substantial body of research utilizing this procedure has been reported in the Soviet literature (Ivanov-Smolensky, 1960). In this work, usually involving children as Ss, the voluntary response usually consisted of squeezing a nubber bulb, the command to "squeeze" or "press" being paired with assorted verbal and nonverbal stimuli serving as the CS.

Although the Soviet researchers imply that Ivanov-Smolensky conditioning is relatively easy to demonstrate, a number of recent studies in this country have met with only partial success in attempts to condition college students to a command UCS (Siebert, Nicholson, Carr-Harris, \& Lubow, 1969; Solberg, 1969; Perlmuter, Fink, Taylor, \& Kimble, 1969). The reason for the relatively low levels of conditioning obtained in these studies is most likely attributable to an active suppression of CRs on the part of most Ss; that is, Ss regard the instructions to respond to the UCS as implying that anticipatory responses to the CS are "incorrect." Apparently, children are not as likely to exhibit such inhibition, a contention supported by the results of a study reported by Hartman (1965) conducted by Dmitrev (1956) showing decreasing levels of Ivanov-Smolensky conditioning as the age of the Ss increased.

The present investigation attempted to replicate this finding using two groups of Ss, one of college age and one of elementary-school age. In addition, some Soviet researchers have reported successful conditioning using various physiological measures of responding (Sokolov \& Paramonova, 1956). Since it is possible that such a measure might provide evidence of anticipatory responding even in the absence of an overt response, simultaneous measures were taken of overt, GSR, and EMG responses.

\section{METHOD}

The elementary-school-age Ss consisted of 20 male children from the 3rd and 4th grades of St. Mary's Grade School, Winona, Minn. Twenty male volunteers from introductory psychology classes at St. Mary's College served as adult Ss.

The $S$ was seated in front of a table within easy reach of a pistol-grip apparatus equipped with a movable trigger. Approximately $18 \mathrm{in}$. in front of the $S$ was a $20 \times 20$ in. opaque screen upon which words could be projected from the rear. The word PRESS served as the UCS and was projected on the screen in block letters by means of a slide projector and attached tachistoscope. The CS consistej of a 40-W electric light bulb mounter at the base of the screen. The onset and termination of these stimuli were automatically controlled by standard commercial equipment. The $S$ was seated in a separate room from all projection and recording equipment. A white-noise generator in the testing room masked extraneous noises.

Three response measures were recorded simultaneously by means of an E \& M Instrument Company Physiograph "Four," consisting of a chart drive and four pen recorders with accompanying amplifiers. A time-event channel was used to mark the onset of the various stimuli. Overt responses were recorded via an isotonic myograph transducer adapted so that any tension applied to the trigger of the pistol grip would be recorded graphically on the physiograph. The EMG readings were taken from a plate electrode attached to the right biceps and a plate electrode attached to the outside surface of the arm in the region of the ulnar nerve just above the right elbow. These electrodes were wired via the appropriate preamplifier to a second channel on the physiograph, allowing the recording of neuroelectrical activity preparatory to and accompanying any muscular response of the hand. In like manner, GSR recordings were taken by means of plate electrodes attached to the left wrist and left index finger.

After the $S$ had been seated and the various electrodes were attached, 10 adaptation trials were given in which the CS appeared alone for $1,660 \mathrm{msec}$. The $\mathrm{S}$ was then told to watch the screen in front of him, and when the word PRESS appeared to press the trigger on the pistol grip as quickly as possible. Forty acquisition trials were then presented in which the CS appeared for a period of $1,660 \mathrm{msec}$ and the UCS for a period of $1,000 \mathrm{msec}$, with an ISI of $660 \mathrm{msec}$. Acquisition was followed by 20 extinction trials in which the CS appeared alone for $1,660 \mathrm{msec}$. The interval between trials varied randomly between 15,20 , and $25 \mathrm{sec}$, with a mean of $20 \mathrm{sec}$. Before each session, care was taken to reassure the $S$ that the experiment was in no way painful or harmful.

\section{RESULTS}

During adaptation and extinction, all responses occurring within the $1,660-\mathrm{msec}$ interval in which the CS appeared were scored as CRs. During acquisition, only those responses occurring within the 660-msec ISI anticipatory to the UCS onset were scored as CRs. The long latency and slow recruitment of the GSR measures precluded meaningful analysis of these results; hence, data are reported only from the EMG and overt measures.

Figure 1 shows the mean per cent CRs at each five-trial block of adaptation, acquisition, and extinction for both children and adults, using both the overt and EMG response measures. During the adaptation period, Ss showed little tendency to respond to the light alone, as measured by either the overt or EMG recordings. During acquisition, neither the children nor the adults showed much evidence of conditioning in terms of overt anticipatory responses, both groups reaching asymptote at about $10 \%$ responding. The EMG measure, on the other hand, showed a rising function of CRs over trials for both groups. An analysis of variance showed the overall difference between the two response measures to be highly significant $[F(1,38)=46.656$, $\mathrm{p}<.001]$, indicating that the EMG measure was much more sensitive in picking up CRs than the actual overt response. In addition, there was a significant overall difference across trials 


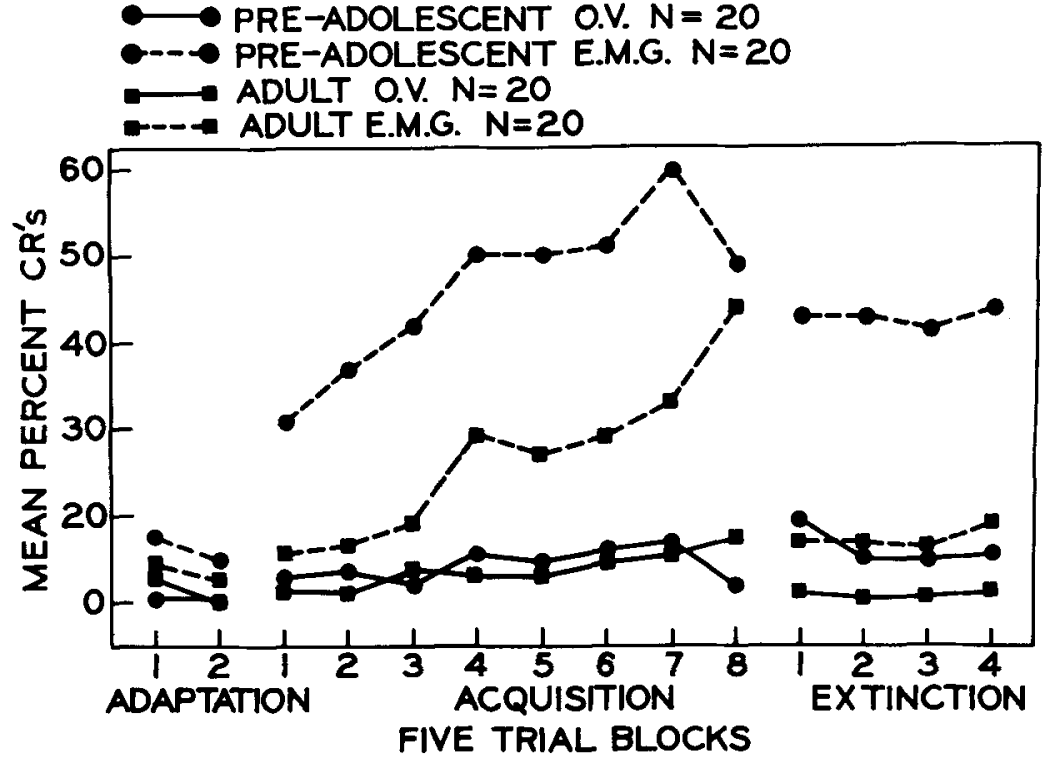

$[F(7,266)=7.046, \quad p<.01]$. However, examination of Fig. 1 suggests that these differences are almost entirely attributable to an increase in EMG responses across trials, a contention supported by a significant interaction between trials and type of measure $[F(7,266)=2.919$, $\mathrm{p}<.05]$. Finally, statistical analysis also showed a significant overall difference between age groups $[\mathrm{F}(1,38)=5.059$, $\mathrm{p}<.05]$. However, once again, examination of Fig. 1 and a significant interaction between age groups and type of measure $[F(1,38)=5.999, p<.05]$ suggests that even though the level of overt responses was about the same for both children and adults, children were much more likely to show an anticipatory EMG response.

During extinction, overt responses remained at a low level for both children and adults, even though the period during which a response could occur and still be scored as a CR was considerably longer during extinction than during acquisition. Responses recorded by the EMG measure dropped to about the same level as overt responses for the adult Ss, while the children continued to show a high level of EMG responses. Analysis of variance of the of a declining response rate over trials. DISCUSSION
Fig. 1. Percentage of CRs over five trial blocks for both adults and children showing both the overt and EMG response measures.

increase in muscle tone or tension anticipating the UCS, is readily conditioned. This preparatory component can be detected by EMG recording, and conditioning can be demonstrated even in the absence of an overt CR.

The finding that the children showed higher response levels than did adults during acquisition and failed to show extinction under the EMG measure would seem to imply that children are less able to inhibit their responses than are adults. This finding might also explain why Soviet researchers using child Ss seem to have had more success in demonstrating Ivanov-Smolensky conditioning than have recent studies in this country using college-age Ss.

extinction data showed a significant overall difference between the two types of measure $[F(1,38)=36.504, p<.001]$, significant overall differences between the two age groups $[\mathrm{F}(1,38)=10.704$, $\mathrm{p}<.01]$, as well as a significant interaction between age level and type of measure $[F(1,38)=6.046, p<.05]$. Thus, in extinction as in acquisition, the EMG measure proved to be significantly more sensitive than the overt measure in recording CRs, with children more likely than adults to show an EMG response. Unlike acquisition, the extinction curves are relatively flat, showing little evidence

Neither the children nor the adults showed any evidence of acquisition or extinction in terms of overt responses to the CS. It would appear that, consistent with other recently reported findings (Siebert, Nicholson, Carr-Harris, \& Lubow, 1969; Solberg, 1969), Ss tended to inhibit overt responses anticipatory to the command UCS. The EMG measure, on the other hand, showed clear evidence of a rising function of CRs during acquisition for both groups of Ss. This suggests that the preparatory component of the UCR, an

\section{REFERENCES}

DMITREV, A. S. On methods of investigation of higher nervous activity in man. Zhurnal Vysshei Nervnoi Deyatel'nosti, 1956, 6, 905-912.

HARTMAN, T. F. Dynamic transmission, elective generalization, and semantic conditioning. In W. F. Prokasy (Ed.), Classical conditioning: $A$ symposium. New York: AppletonCentury-Crofts, 1965. Pp. 90-106.

IVANOV-SMOLENSKY, A. G. Works of the Institute of Higher Nervous Activity: Patho-physiological series Vol. 2. Moscow, U.S.S.R: Academy of Science, 1956. (Translated, Israel Program for Scientific Translations for the NSF, U.S.A., 1960.)

PERLMUTER, L. C., FINK, A. M., TAYLOR, G. A., \& KIMBLE, G. A. The effect of the interstimulus interval on the conditioning of voluntary instructed responses. Journal of Experimental Psychology, 1969, 79, 403-405.

SIEBERT, L., NICHOLSON, E. C., CARR-HARRIS, E., \& LUBOW, R. E. Conditioning by the method of Ivanov-Smolenski. Journal of Experimental Psychology, 1969, 79, 93-96.

SOKOLOV, E. N., \& PARAMONOVA, N. P. Concerning the role of the orientation reflex in the formation of motor conditioned reactions in man. Journal of Higher Nervous Activity, 1956, 6, 702-709. Cited by E. N. Sokolov, Perception and the conditioned reflex. New York: Pergamon Press, 1963.

SOLBERG, K. B. Classical eyelid conditioning to a command UCS. Unpublished MA thesis, University of Wisconsin, 1969. 